\title{
An assessment of the vaccination of school-aged children in England
}

\author{
Matt J. Keeling ${ }^{1,2}$ Sam E. Moore ${ }^{1,2}$
}

1 The Zeeman Institute for Systems Biology \& Infectious Disease Epidemiology Research, School of Life Sciences and Mathematics Institute, University of Warwick, Coventry, CV4 7AL, UK.

2 Joint UNIversities Pandemic and Epidemiological Research, https://maths.org/juniper/

Background Children and young persons are known to have a high number of close interactions, often within the school environment, which can facilitate rapid spread of infection; yet for SARS-CoV-2 it is the elderly and vulnerable that suffer the greatest health burden. Vaccination, initially targeting the elderly and vulnerable but later expanded to the entire adult population, has been transformative in the control of SARS-CoV-2 in England. However, early concerns over adverse events and the lower risk associated with infection in younger individuals means that the expansion of the vaccine programme to those under 18 year of age needs to be rigorously and quantitatively assessed.

Methods Here, using a bespoke mathematical model matched to case and hospital data for England, we consider the potential impact of vaccinating 12-17 and 5-11 year olds. This analysis is reported from an early model (generated in June 2021) that formed part of the evidence base for the decisions in England, and a later model (from November 2021) that benefits from a richer understanding of vaccine efficacy, greater knowledge of the Delta variant wave and uses data on the rate of vaccine administration. For both models we consider the population wide impact of childhood vaccination as well as the specific impact on the age-group targeted for vaccination.

Results Projections from June suggested that an expansion of the vaccine programme to those 12-17 years old could generate substantial reductions in infection, hospital admission and deaths in the entire population, depending on population behaviour following the relaxation of control measures. The benefits within the 12-17 year old cohort were less marked, saving between 656 and 1077 (95\% prediction interval 281-2260) hospital admissions and between 22 and 38 (95\% PI 9-91) deaths depending on assumed population behaviour. For the more recent model, the benefits within this age group are reduced, saving on average 631 (95\% PI 304-1286) hospital admissions and 11 (95\% PI 5-28) deaths for $80 \%$ vaccine uptake, while the benefits to the wider population represent a reduction of $8-10 \%$ in hospital admissions and deaths. The vaccination of 5-11 year olds is projected to have a far smaller impact, in part due to the later roll-out of vaccines to this age-group.

Conclusions Vaccination of 12-17 year olds and 5-11 year olds is projected to generate a reduction in infection, hospital admission and deaths for both the age-groups involved and the population in general. For any decision involving childhood vaccination, these benefits needs to be balanced against potential adverse events from the vaccine, the operational constraints on delivery and the potential for diverting resources from other public health campaigns.

Keywords: COVID-19, immunisation, infection, hospital admission. 


\section{Background}

The SARS-CoV-2 pandemic has lead to severe healthcare burdens, often necessitating unprecedented non-pharmaceutical intervention measures[1? ? , 2]. From December 2020, the availability of highly effective vaccines (first the Pfizer-BioNTech, followed by the Oxford-AstraZeneca and Moderna vaccines) offered an alternative method for limiting infection and disease[3-5]. In England, this led to the largest ever vaccine campaign with around 100 million doses administered in the first twelve months. These vaccines were offered in a targeted manner, with healthcare workers, the vulnerable and the elderly being the first to be offered their initial dose[6].

One of the key characteristics of the SARS-CoV-2 pandemic has been the striking age-dependent nature of disease severity, with older (and clinically vulnerable) individuals suffering a far higher burden of hospital admissions and deaths [7-10]. Many countries initially closed schools as a response to this pandemic [11-14], but the role played by school-aged children and the strength of transmission within the school environment remain deeply contested with different conclusions being drawn from a range of modelling and data-driven analyses [15-31]. This dichotomy of views on the role of schools may be attributed to two conflicting factors. Firstly, all the available data highlights that younger individuals have a lower susceptibility to SARS-CoV-2 infection, a reduced risk of displaying symptoms and a greatly reduced risk of severe illness [7-9,31]. However, it is also well established that the school environment is historically associated with a high transmission risk for many respiratory pathogens [3236], simply due to the large number of pupils and the high number of contacts involved [37-39]. The data from England suggests that (until the Omicron variant) there had not been the types of explosive outbreaks of SARS-CoV-2 within schools that are frequently associated with other respiratory diseases [40-43]; yet it is evident that transmission does occur within schools [44-46] and much of 2021 saw pronounced increases in school-aged infection in England [42, 47].

Here a complex age-structured model, matched to data in the seven NHS regions of England [4850], is used to examine the vaccination of 12-17 and 5-11 year olds. In particular, the number of infections, hospital admissions and deaths in the whole population and in the target age-groups are compared with and without vaccination. The model has been extensively used throughout the pandemic, particularly for questions about vaccination [50, 51] and to project the likely impact of relaxing control measures $[52,53]$. This model formulation has also been used to consider the impact of school reopening on the population level incidence [15], although bespoke individual-scale models may be more appropriate when focusing on within-school dynamics rather than their feed-back on the community $[24,54,55]$.

We consider the projected dynamics and the benefits from the perspective of a pre-Omicron assessment. The rapid spread of the Omicron variant has dramatically shifted the epidemiological landscape with far more infections expected in England during very early 2022. However, there are currently too many uncertainties surrounding fundamental parameters associated with this new variant to make robust quantitative projections.

The aim of this paper is not to argue for or against vaccination of particular age-groups, but to present a quantitative assessment of the epidemiological role that vaccination has played and is likely to play in the near future. As such the paper focuses on the positives of vaccination: the impact of vaccinating children and young people on the infection in the vaccinated age-group in particular and the population in general. There is no quantitative consideration or comparison of these benefits against potential risks or costs. 


\section{Methods}

Three sets of simulations are performed: one from 26th June 2021 which was used as part of the JCVI decision-making process for the vaccination of 12-17 year olds; one using data and information up to 6th November 2021 again looking at the benefits of vaccinating 12-17 year olds; and a final simulation based on 6th November data examining the benefit of vaccinating 5-11 year olds.

The model used throughout this paper is an age-structured formulation that has been developed throughout this pandemic $[15,48,53]$ and has been continually matched to a range of epidemiological data [49]. The model is explained in more detail in the Supplementary Material, but a brief overview of the main characteristics are given here. The model is a deterministic age-structured model, partitioning the population into twenty-one 5-year age classes and partitioned spatially into the seven NHS regions of England. The model captures age-dependent mixing, susceptibility, likelihood of symptoms and likelihood of severe disease. It has been adapted throughout the course of the pandemic to include multiple variants $[56]$ and vaccination $[6,50]$. The November model also includes the waning of vaccine protection and infection-derived immunity as well as the deployment of booster vaccination. One of the principal drivers of epidemic behaviour is the mixing of individuals in the population, which can be modified by either as a result of imposed restrictions or voluntary behaviour change due to perceived risk. This level of precautionary behaviour is inferred as a slowly varying parameter by matching to recorded numbers of community test results, hospital admissions and hospital bed occupancy, ICU occupancy and deaths in each of the seven spatial regions.

The model is used to investigate the number of infections, hospital admissions and deaths using a weighted sum over a given time frame (we define $w_{d}$ as the weighting applied on day $d$ ). Numbers with and without the vaccination of children are compared, considering both the total numbers across the entire population and numbers in the cohort being vaccinated. The results generated in June 2021 and presented to JCVI used a time window of 19th July 2021 until 31st December 2021 and weighted all time-points equally - with 19th July chosen as the start of Step 4 and the lifting of restrictions. However, it is arguably more appropriate to consider a longer time window (19th July 2021 until 31st December 2022) so that the longer impact of immunisation can be captured. We do this by having a constant weighting applied from 19th July to 31st December 2021, as previously, followed by weights that decrease linearly to zero by 31 st December 2022 . This gradual decline accounts for the greater uncertainty in longer-term projections and has the advantage over a discrete step-change that the results are relatively insensitive to the timing of future waves of infection. In the earlier step-change formulation a wave of infection in December 2021 would be included in the sum, but one in January 2022 would not; the use of a longer window with a gradual decline in the weighting overcomes many of these problems. The use of such a weighted time window draws into sharp focus the need to specify the total time frame over which any vaccine programme is evaluated; we quantify this by calculating the programme weighting, $T_{V}$, which is the total weighted time over which the vaccination of the target cohort operates:

$$
T_{V}=\frac{\sum_{d} V_{d} \sum_{D>d} w_{D}}{\sum_{d} V_{d}}
$$

where $V_{d}$ is the number of individuals in the cohort vaccinated on day $d$.

\section{June Projections}

The model from the 26th June, was based on the model framework used for the 6th July Roadmap [53]. Vaccination of 12-17 year olds was included as part of the national vaccine roll-out, which was assumed to administer 2 million doses a week from late July onwards, such that 12-17 years would be offered vaccination once older groups had been offered theirs. Throughout it was also assumed that $80 \%$ of this age-group would take the vaccine. Given the need to first vaccinate those over 18 years old and 
to offer second doses at the correct time, the vast majority of first doses in the 12-17 age group take place between early August and late September 2021. It was assumed that second doses are given no sooner that 8 weeks after the first dose, with precise timing depending on the vaccine schedule leading to the majority of second doses in 12-17 year olds being administered between early October and late November 2021 (Figure 1).

In late June 2021 the vaccine efficacy against the newly emerged Delta variant remained highly uncertain, with the best estimates suggesting limited impact from the first dose but markedly increased protection from the second dose. Although 12-17 year olds were largely given the Pfizer vaccine, Table 1 presents vaccine efficacy values from the time for both AstraZeneca and Pfizer as the protection from AstraZeneca is important for the rest of the population.

\begin{tabular}{|c|c|c|c|c|}
\hline & \multicolumn{2}{|c|}{ AstraZeneca } & \multicolumn{2}{c|}{ Pfizer } \\
Protection against: & Dose 1 & Dose 2 & Dose 1 & Dose 2 \\
\hline Infection & $34 \%$ & $71 \%$ & $34 \%$ & $73 \%$ \\
\hline Symptoms & $34 \%$ & $82 \%$ & $34 \%$ & $83 \%$ \\
\hline Hospitalisation & $64 \%$ & $90 \%$ & $64 \%$ & $91 \%$ \\
\hline Deaths & $60 \%$ & $96 \%$ & $60 \%$ & $96 \%$ \\
\hline
\end{tabular}

Table 1: Estimated vaccine efficacy (from the June projections) against infection, symptomatic disease, hospital admission and death after one or two doses with either the AstraZeneca ChAdOx vaccine or an mRNA vaccine such as the Pfizer vaccine. Values were taken from PHE reports at the time.

These June simulations were performed before 'Step 4' (on 19th July 2021) and the complete relaxation of all restrictions on social mixing; therefore a range of future possibilities were explored from an abrupt return to pre-COVID social mixing to a gradual return over several months. This uncertainty in population behaviour determines the scale and shape of the Delta wave, with more rapid returns to pre-COVID mixing leading to higher but shorter waves of infection.

Simulation results are aggregated either across the short-term time window (19th July - 31st December 2021, with equal weighting on all days) or the longer-term window (with constant weighted from 19th July - 31st December 2021, and then a linearly declining weighting until 31st December 2022). For vaccinations that begin in early August, this means that the short-term window has a programme weighting of 134 days over which childhood vaccination can impact the dynamics, which extends to around 316 days for the longer-term window.

\section{November Projections}

The more recent model uses data and parameters up to 6th November to perform similar analyses, this data includes updated vaccine efficacy estimates (Table 2) which provide greater protection especially after the first dose compared to the earlier estimates. However, by this point in time, data were also accumulating on the efficacy of vaccines over time, with a strong signal of waning protection. Given this observation, from September 2021 booster (third) doses were offered to individuals who had received their second dose of vaccine more than six months ago. Both waning and boosters are included in the updated model framework [51].

Given that the uncertainties in behaviour associated with the transition to Step 4 have been resolved, the November model focuses on a range of other unknowns including the speed of vaccine delivery and the uptake. By this point it was known that vaccination of 12-15 year olds was taking place in the school environment separating it from the logistical demands of vaccinating the rest of the population, while first doses had been offered to 16-17 year olds since August 2021. It is generally considered more equitable to vaccinate children though a school-based system, which also generally 
achieves better up-take than other methods. In these simulations the counterfactual scenario in which 12-17 year olds are not vaccinated is first considered; this is compared to projections that use the observed vaccinations until 6th November (by which time $70 \%$ of $16-17$ year olds and $40 \%$ of $12-15$ year olds have received one dose) and then continue vaccinating 12-15 year olds into the future until the required uptake $(60 \%, 70 \%$ or $80 \%)$ is achieved (Figure 1$)$. Sensitivity to the rate at which the vaccine roll-out continues from 6th November onwards is explored, vaccinating either 100,000, 140,000 or 180,000 12-15 year old pupils per week. For simplicity it is assumed that a second dose is given 12 weeks after the first (Figure 1).

For these November simulations only the longer-term window is used (with constant weighting from 19th July - 31st December 2021, and then a linearly declining weighting until 31st December 2022). Given that vaccination of 12-15 year olds began on 20th September 2021 and continued throughout 2021, this means that childhood vaccination has a programme weighting of 267 days.

\begin{tabular}{|c|c|c|c|c|}
\hline & \multicolumn{2}{|c|}{ AstraZeneca } & \multicolumn{2}{c|}{ Pfizer } \\
Protection against: & Dose 1 & Dose 2 & Dose 1 & Dose 2 \\
\hline Infection & $45 \%$ & $70 \%$ & $55 \%$ & $85 \%$ \\
\hline Symptoms & $45 \%$ & $70 \%$ & $55 \%$ & $90 \%$ \\
\hline Hospitalisation & $80 \%$ & $95 \%$ & $80 \%$ & $95 \%$ \\
\hline Deaths & $80 \%$ & $98 \%$ & $80 \%$ & $98 \%$ \\
\hline
\end{tabular}

Table 2: Estimated vaccine efficacy from the November models against infection, symptomatic disease, hospital admission and death after one or two doses with either the AstraZeneca ChAdOx vaccine or an mRNA vaccine such as the Pfizer vaccine. Values are taken from UKHSA reports [57, 58]

This more recent model is also used to examine the vaccination of 5-11 year olds, assuming that this begins in March 2022, once second doses of 12-15 years is largely complete - logistical constraints make it unlikely that school-based programmes for 12-15 year olds and 5-11 year olds could operate in parallel. Vaccination of this age-group is assumed to be through the school environment and a range of vaccine uptake levels $(60 \%, 70 \%$ and $80 \%)$ and a range of deployment speeds (slow - 100,000 per week, default - 140,000 per week or fast - 180,000 per week) are considered as part of the sensitivity analysis (Figure 1). Given that there are approximately 87\% more 5-11 year olds than 12-15 year olds in England, vaccination of this cohort is a far lengthier process. The longer-term window is again used, which given that vaccination does not begin until March 2022, means that vaccination of 5-11 year olds has a programme weighting of only 81 days.

\section{Results}

We begin by comparing age-structured model output (from the June and November models) against the data in terms of the number of individuals admitted to hospital in ten different age-groups, from 0-5 to over 85 years old (Figure 2). The June results (which are an average over the seven Step 4 scenarios investigated [53], including vaccination of 12-17 year olds) highlight an underestimation of the epidemic scale, but an overestimation of young people being hospitalised - this is principally due to the inability to forecast population level mixing in response to the Step 4 relaxation step. For the November simulations, there is a much closer agreement between model results and the data. These later replicates were performed by fitting to the total hospital admissions (without age-structure) over this period, so have been matched to the historic changes in imposed restrictions and precautionary mixing that drive the dynamics. Nevertheless, this comparison acts as a relatively independent assessment of the model fit, as age-structured data is not used as part of the inference process. 


\section{June Predictions}

The projections generated in June 2021 had to make assumptions about the population mixing that would occur under Step 4 of the relaxation roadmap when all legal restrictions on social mixing were removed. A range of scenarios were investigated (bottom row, Figure 3), from an abrupt return to pre-COVID mixing (shown in purple and pink) to a far more gradual return (shown in green and cyan). Unsurprisingly, a rapid return to pre-COVID mixing leads to a single sharp peak in infection and hospital admissions, whereas a more gradual return often leads to a multi-peaked wave. These plots of the total number of hospital admissions show results without (solid line) and with (dashed line) the vaccination of $12-17$ year olds.

The impact of childhood vaccination on the age-classes concerned (top row, Figure 3) leads to a reduction in the total number of infections (left), hospital admissions (centre) and deaths (right) that are projected to be accrued over the period 19th July 2021 to 31st December 2022, with the appropriate temporal weighting. Similar results but only over the period 19th July 2021 to 31st December 2021 are given in the Supplementary Material. The assumption about relaxation to pre-COVID behaviour (different colours in Figure 3) has a large effect on the dynamics and hence the impact of vaccines on the 12-17 year old age group. In general the results suggest that vaccination of 12-17 years reduces infection in the same age group by 200-400 thousand, reduces hospital admissions by around 600-1100, and reduces death by around 20-40 individuals, although the $95 \%$ prediction intervals on each of these are large showing the considerable uncertainty in the dynamics.

Broadening our scope to the entire population (middle row, Figure 3) shows the total number of infections, hospital admission and deaths over the time frame, both with (front lighter bars) and without (rear darker bars) vaccination of 12-17 year olds. The top bar that is unfilled corresponds to the numbers in the 12-17 age group, hence the difference between the two unfilled bars is the value shown in the top row. Error bars refer to the uncertainty in the total values. As expected, the assumptions about mixing after Step 4 on 19th July 2021 have a substantial impact on the total numbers predicted and the impact of vaccinating 12-17 year olds. Slow relaxation to pre-COVID mixing (e.g. green) leads to both lower totals and a greater impact of vaccination as the longer second (relaxation) wave generated when $R$ just exceeds one is suppressed by vaccination. In contrast, for rapid relaxation (e.g. pink) there is insufficient time for the vaccination of 12-17 years to substantially reduce the infection dynamics. These graphs also highlight the lower severity of disease generally experienced by younger age groups; the fraction of each bar that is unfilled (representing those aged 12-17 years old) decreases substantially from infection, to hospital admission, to death.

\section{November Predictions, 12-17 year olds}

Rerunning similar analysis in November, with greater understanding of vaccine efficacy against the Delta variant and hindsight for the social mixing after Step 4, leads to broadly similar patterns (Figure 4). The lower panels again show examples of the total number of daily hospital admissions projected over time, together with the temporal weighting that is applied between 19th July 2021 and 31st December 2022. In these panels the black curve (and associated 95\% prediction interval) refers to the counterfactual epidemic in the absence of childhood vaccination, while the blue, green and red curves show the impact of childhood vaccination with a slow, default and fast roll-out from November onward, respectively.

Focusing on the implications for vaccination of 12-17 year olds on this age-group (top row, Figure 4), delivery speed (blue, green and red) has relatively limited impact on the dynamics - in part because the vaccination of 12-17 year old up to 6th November 2021 is set by the observed schedule, which also restricts the timing of second doses. There is a more pronounced impact of vaccine uptake, with higher uptakes generating a greater impact. As seen with the earlier projections, there is a far greater 
reduction in infections compared to hospital admissions compared to deaths. Contrasting the June and November results, shows a lower benefit (approximately halved) in all three measures from the revised November model compared to the results from June. This is partly attributable to the larger wave of infection from July to December 2021 in the November simulations compared to some of the June scenarios; in terms of epidemic scale the November simulations most closely match the pink June scenario which has the lowest impact of vaccinating 12-17 year olds.

When considering the impact of vaccinating 12-17 year olds on the entire population (middle row, Figure 4), this again highlights that while infections in the 12-17 age group are relatively common (unfilled bar compared to the total height), hospital admissions and deaths are far less frequent in this age-group. These plots compare the counterfactual model without childhood vaccination (grey bar) with the vaccination of 12-17 year olds at different deployment speeds (after 6th November) and with different uptakes. Compared to the June results, the impact of childhood vaccination is diminished in the November simulations, with none of the later results generating the larger reductions that were projected for some of the Step 4 scenarios. This reduced impact of vaccination can be attributed to multiple factors: the difference in the pattern and scale of infection between July and December 2021, the higher vaccine efficacy assumptions in November such that the majority of the older population have greater protection and the slower roll-out schedule compared to earlier estimates.

\section{November Predictions, 5-11 year olds}

Switching attention to the vaccination of younger children aged 5-11 years, it is assumed that their vaccination begins in March 2022, by which time the majority of older children (12-17) will have already been offered two doses. This later start date, coupled with the temporal weighting applied to all sums, means that there is less time (and less weight at each time point) for the vaccine to register an impact; the programme weighting has been reduced to 81 days. Therefore, while it makes sense to compare different scenarios for vaccination of 5-11 year olds, it is difficult to compare between the two childhood programs (12-17 year olds vs 5-11 year olds) due to the different time-frames involved - earlier vaccination will inevitably generate greater impacts.

Considering the impact of vaccinating 5-11 year olds on infection and disease in the 5-11 year old agegroup (top panels, Figure 5) delivery speed (blue - slow, green - default, red - fast) has a pronounced impact as the entire delivery programme is now being simulated. The impact of vaccine uptake is most pronounced when the roll-out is fast, as this achieves the maximum coverage in the shortest amount of time, before these individuals become infected. For all these results, the lower bound of the $95 \%$ prediction intervals is close to zero, showing that in $2.5 \%$ of the projections the vaccination of $5-11$ year olds is ineffective as there is predicted to be a substantial wave of infection in this age-group before vaccine delivery starts.

Again considering the impact on the entire population of vaccinating this youngest age-group (bottom row, Figure 5) highlights that vaccination of 5-11 year olds has a minimal effect on the rest of population, partly due to the late start to the vaccine campaign such that older individuals are already protected by immunization or infection.

\section{Discussion}

The SARS-CoV-2 immunisation programme for children and young persons in England has evolved in an iterative manner, which is reflected in the timing of vaccinations in the later model. From late July (JCVI advice published 19th July 2021 [59]) those aged 12-17 with specific underlying health conditions that put them at risk of serious COVID-19 were offered the vaccine. This was extended in August (JCVI advice published 4th August 2021 [60]) to a first dose to all 16-17 year olds, a second 
dose 12 weeks later (JCVI advice published 15th November 2021 [61]) and a booster dose after 3 months (JCVI advice published 22nd December 2021 [62]). Those aged 12-15 (and not in a high-risk category) were offered their first doses through schools from late September (JCVI advice published 3rd September 2021 [63]), with a second dose 12 weeks later (JCVI advice published 29th November 2021 [64]). Finally, at-risk 5-11 year olds with specific underlying health conditions that put them at risk of serious COVID-19 were offered the vaccine from late December 2021 (JCVI advice published 22nd December 2021 [62]).

As can be seen from the decisions for England, there are considerable advantages in (initially) targeting vaccination to the most vulnerable[65, 66] - applying equally well to both adults and children. Available data suggests that clinically vulnerable children comprise around half of hospital admissions and three quarters of deaths in this age-group $([10,67])$, so protecting these individuals first with early targeted vaccination provides the greatest immediate impact. Due to a lack of available data, vulnerable groups have not been explicitly captured within our model; instead the risks (as captured by the infection:hospital ratio or infection:mortality ratio) are an average over all individuals within a fiveyear age-group. As such our results pertain to the advantages of vaccinating entire age cohorts; once the vulnerable have been offered the vaccine, the benefit of vaccinating the non-vulnerable is likely to be significantly reduced. Calculating the size of this reduction is not simply a matter of scaling down hospital admissions and deaths, but also needs to account for the indirect impact of vaccination (protection due to the reduction of infection) in this target age-group.

This paper has focused on the epidemiological impacts of vaccinating 5-17 year olds; calculating the reduction in infection, hospital admissions and deaths over a given time period. Using the November projections, we would estimate a reduction of approximately 250 thousand infections, 600 hospital admissions and 10 deaths in the 12-17 year old age-group over the time-period studied, if at least $60 \%$ of this cohort were vaccinated; and an additional reduction of 40-60 thousand infections and 40-60 hospital admissions in the 5-11 year old age-group when vaccinating this younger age. In part the lower numbers from the vaccination of 5-11 year olds comes from the lower programme weighting: 81 days compared to 267 days - due to the later impacts of the programme.

When considering the implementation of any new vaccine program it is important to consider the potential risks and costs as well as simply the expected benefits. In England, it is usually common to formulate a cost-benefit analysis in terms of financial costs of the vaccine against the benefit in terms of QALYs gained[68, 69] - although this approach has not been used when considering vaccination against SARS-CoV-2. In addition, there is now evidence that the general public expect the benefits of immunisation to substantially outweigh any health risk associated with adverse events of vaccination[70]. In this context, there were considerable early concerns about the risks of myocarditis and pericarditis following vaccination in younger individuals[71-74], and the potential for such adverse effects to disrupt the public's confidence in the entire vaccination programme. However, there are clearly benefits associated with vaccination of 5-17 year olds; while the saving in terms of hospital admission and deaths is moderate compared to the total numbers observed so far, the benefits to the vaccine cohorts especially in terms of minimising infection and associated risks or minimising educational losses is clear.

There are several factors that could be introduced into the modelling framework to increase its realism. As mentioned above, being able to separate the younger population into vulnerable and non-vulnerable individuals would mean that the models would more closely replicate the pattern of vaccine roll-out deployed in England. While the model generates the number of infections and hospital admissions due to COVID-19, it does not attempt to quantify long-COVID - in part due to a lack of clinical definition and hence a lack of national-scale data[75, 76]. For some scenarios, the number of individuals involved is relatively small (e.g. the reduction in deaths in 5-11 year olds due to vaccinating 5-11 year olds) in 
medRxiv preprint doi: https://doi.org/10.1101/2022.02.04.22270361; this version posted February $6,2022$. The copyright holder for this preprint (which was not certified by peer review) is the author/funder, who has granted medRxiv a license to display the preprint in

It is made available under a CC-BY-NC-ND 4.0 International license .

which case it may be beneficial to adopt a stochastic approach such that the numbers predicted are all integers. Finally, the models do not include the Omicron variant; data on this new variant are still relatively sparse prohibiting the ability to make robust long-term projections. A substantial Omicron wave in early 2022 would likely increase the benefits of vaccinating 12-17 year olds as they would have protection against this increase in infection; however if would likely reduce the benefits of vaccinating 5-11 year olds as they are unlikely to be vaccination before any peak of the Omicron wave. The lower vaccine efficacy and lower severity reported for the Omicron variant could also reduce the benefits of childhood vaccination - more data is needed before detailed simulations can be performed.

\section{Conclusions}

We have shown that vaccination of 12-17 year olds, and to a lesser extent the vaccination of 5-11 year olds, reduces infection, hospital admissions and deaths. These reductions were projected to be higher when modelling the dynamics in June compared to November 2021, partly due to an assumption of more rapid vaccine delivery and partly due to the unexpected scale of the third wave from July to December 2021. The projections from November 2021 suggest the vaccination of 12-17 year olds will generate a saving of around 600 (PI 280-1280) hospital admissions and a reduction of around 280,000 (PI 200,000-380,000) infections in this age group; while without vaccination we project 2240 (PI 12804000) hospital admissions and 1.3 million (PI 1.0-1.6 million) infections. The decision whether to offer vaccination to these younger individuals must balance the benefits to both the vaccinated age-group and the population in general against the risks of adverse events and the potential disruption to a range of other public health activities. 
medRxiv preprint doi: https://doi.org/10.1101/2022.02.04.22270361; this version posted February 6, 2022. The copyright holder for this preprint (which was not certified by peer review) is the author/funder, who has granted medRxiv a license to display the preprint in

It is made available under a CC-BY-NC-ND 4.0 International license .

\section{Ethical considerations}

Data from the CHESS and SARI databases were supplied after anonymisation under strict data protection protocols agreed between the University of Warwick and Public Health England. The ethics of the use of these data for these purposes was agreed by Public Health England with the Government's SPI-M(O) / SAGE committees.

\section{Consent for publication}

Not Applicable.

\section{Availability of data and materials}

Data on cases were obtained from the COVID-19 Hospitalisation in England Surveillance System (CHESS) data set that collects detailed data on patients infected with COVID-19. Data on COVID19 deaths were obtained from Public Health England. These data contain confidential information, with public data deposition non-permissible for socioeconomic reasons. The CHESS data resides with the National Health Service (www.nhs.gov.uk) whilst the death data are available from Public Health England (www.phe.gov.uk). The ethics of the use of these data for these purposes was agreed by Public Health England with the Governments SPI-M(O) / SAGE committees. More aggregate data is freely available from the UK Coronavirus dashboard: https://coronavirus.data.gov.uk/

\section{Competing Interests}

The authors declare that they have no competing interests.

\section{Patient and public involvement}

This was an urgent public health research study in response to a Public Health Emergency of International Concern. Patients or the public were not involved in the design, conduct, or reporting of this rapid response research.

\section{Funding}

MJK and SEM are funded by the National Institute for Health Research (NIHR) [Policy Research Programme, Mathematical and Economic Modelling for Vaccination and Immunisation Evaluation, and Emergency Response; NIHR200411]; MJK is also funded through the JUNIPER modelling consortium [grant number MR/V038613/1]. MJK is affiliated to the National Institute for Health Research Health Protection Research Unit (NIHR HPRU) in Gastrointestinal Infections at University of Liverpool in partnership with UK Health Security Agency (UKHSA), in collaboration with University of Warwick. MJK is also affiliated to the National Institute for Health Research Health Protection Research Unit (NIHR HPRU) in Genomics and Enabling Data at University of Warwick in partnership with UK Health Security Agency (UKHSA). The views expressed are those of the author(s) and not necessarily those of the NHS, the NIHR, the Department of Health and Social Care or UK Health Security Agency. 
medRxiv preprint doi: https://doi.org/10.1101/2022.02.04.22270361; this version posted February 6, 2022. The copyright holder for this preprint (which was not certified by peer review) is the author/funder, who has granted medRxiv a license to display the preprint in It is made available under a CC-BY-NC-ND 4.0 International license.

\section{Author Information}

MJK performed the analysis, interpreted the results and was the major contributor in writing the manuscript. SM developed the early simulation software and contributed to the overall conception and design of the work. All authors read and approved the final manuscript. 
medRxiv preprint doi: https://doi.org/10.1101/2022.02.04.22270361; this version posted February 6, 2022. The copyright holder for this preprint (which was not certified by peer review) is the author/funder, who has granted medRxiv a license to display the preprint in

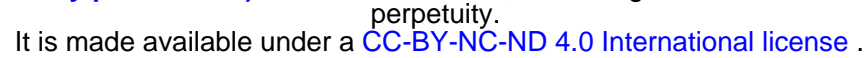

\section{References}

[1] Brauner JM, Mindermann S, Sharma M, Johnston D, Salvatier J, et al. Inferring the effectiveness of government interventions against COVID-19. SCIENCE 371(6531):802+ (2021). doi:\{10. 1126/science.abd9338\}.

[2] Liu Y, Morgenstern C, Kelly J, Lowe R, Jit M, et al. The impact of non-pharmaceutical interventions on SARS-CoV-2 transmission across 130 countries and territories. BMC MEDICINE 19(1) (2021). doi:\{10.1186/s12916-020-01872-8\}.

[3] Polack FP, Thomas SJ, Kitchin N, Absalon J, Gurtman A, et al. Safety and Efficacy of the BNT162b2 mRNA Covid-19 Vaccine. N. Engl. J. Med. 383(27):2603-2615 (2020). doi:10.1056/ NEJMoa2034577.

[4] Voysey M, Clemens SAC, Madhi SA, Weckx LY, Folegatti PM, et al. Safety and efficacy of the ChAdOx1 nCoV-19 vaccine (AZD1222) against SARS-CoV-2: an interim analysis of four randomised controlled trials in Brazil, South Africa, and the UK. Lancet 397(10269):99-111 (2021). doi:10.1016/S0140-6736(20)32661-1.

[5] Pritchard E, Matthews PC, Stoesser N, Eyre DW, Gethings O, et al. Impact of vaccination on new sars-cov-2 infections in the uk. Nature Medicine (2021).

[6] Moore S, Hill EM, Dyson L, Tildesley MJ, Keeling MJ. Modelling optimal vaccination strategy for sars-cov-2 in the uk. PLoS computational biology 17(5):e1008849 (2021).

[7] Ludvigsson JF. Systematic review of COVID-19 in children shows milder cases and a better prognosis than adults. Acta Paediatrica, International Journal of Paediatrics 109(March):10881095 (2020). doi:10.1111/apa.15270.

[8] Viner RM, Mytton OT, Bonell C, Melendez-Torres G, Ward JL, et al. Susceptibility to and transmission of COVID-19 amongst children and adolescents compared with adults: a systematic review and meta-analysis. medRxiv page 2020.05.20.20108126 (2020). doi:10.1101/2020.05.20. 20108126 .

[9] Barton M, Mehta K, Kumar K, Lu J, le Saux N, et al. COVID- 19 Infection in Children: Estimating Pediatric Morbidity and Mortality. medRxiv preprint pages 1-26 (2020).

[10] Smith C, Odd D, Harwood R, Ward J, Linney M, et al. Deaths in children and young people in england after sars-cov-2 infection during the first pandemic year. Nature medicine pages 1-8 (2021).

[11] DELVE. Balancing the Risks of Pupils Returning to Schools (2021). URL https://rs-delve. github.io/reports/2020/07/24/balancing-the-risk-of-pupils-returning-to-schools.html. [Online] (Accessed: 15 July 2021).

[12] Courtemanche C, Garuccio J, Le A, Pinkston J, Yelowitz A. Strong Social Distancing Measures In The United States Reduced The COVID-19 Growth Rate. Health Aff. page 10.1377/hlthaff.2020.00608 (2020). doi:10.1377/hlthaff.2020.00608.

[13] Viner RM, Russell SJ, Croker H, Packer J, Ward J, et al. School closure and management practices during coronavirus outbreaks including COVID-19: a rapid systematic review. Lancet Child Adolesc. Heal. 4(5):397-404 (2020). doi:10.1016/S2352-4642(20)30095-X. 
medRxiv preprint doi: https://doi.org/10.1101/2022.02.04.22270361; this version posted February 6, 2022. The copyright holder for this preprint (which was not certified by peer review) is the author/funder, who has granted medRxiv a license to display the preprint in It is made available under a CC-BY-NC-ND 4.0 International license .

[14] Koestner C, Letzel S, Eggert V, Beutel T, Dietz P. Comparing SARS-CoV-2 case rates between pupils, teachers and the general population: results from Ger-many. medRxiv page 2021.03.04.21252877 (2021). doi:10.1101/2021.03.04.21252877.

[15] Keeling MJ, Tildesley MJ, Atkins BD, Penman B, Southall E, et al. The impact of school reopening on the spread of covid-19 in england. Philosophical Transactions of the Royal Society B 376(1829):20200261 (2021).

[16] Munday JD, Sherratt K, Meakin S, Endo A, Pearson CAB, et al. Implications of the schoolhousehold network structure on SARS-CoV-2 transmission under school reopening strategies in England. Nat. Commun. 12:1942 (2021). doi:10.1038/s41467-021-22213-0.

[17] Lessler J, Grabowski MK, Grantz KH, Badillo-Goicoechea E, Metcalf CJE, et al. Household COVID-19 risk and in-person schooling. medRxiv page 2021.02.27.21252597 (2021). doi:10.1101/ 2021.02.27.21252597.

[18] Panovska-Griffiths J, Stuart RM, Kerr C, Rosenfeld K, Mistry D, et al. Modelling the impact of reopening schools in early 2021 in the presence of the new SARS-CoV-2 variant and with roll-out of vaccination against COVID-19. medRxiv page 2021.02.07.21251287 (2021). doi:10.1101/2021. 02.07.21251287.

[19] Panovska-Griffiths J, Kerr CC, Stuart RM, Mistry D, Klein DJ, et al. Determining the optimal strategy for reopening schools, the impact of test and trace interventions, and the risk of occurrence of a second COVID-19 epidemic wave in the UK: a modelling study. Lancet Child Adolesc. Heal. 4(11):817-827 (2020). doi:10.1016/S2352-4642(20)30250-9.

[20] Gandini S, Rainisio M, Iannuzzo ML, Bellerba F, Cecconi F, et al. No evidence of association between schools and SARS-CoV-2 second wave in Italy. medRxiv page 2020.12.16.20248134 (2020). doi:10.1101/2020.12.16.20248134.

[21] Di Domenico L, Pullano G, Sabbatini CE, Boëlle PY, Colizza V. Modelling safe protocols for reopening schools during the COVID-19 pandemic in France. Nat. Commun. 12:1073 (2021). doi:10.1038/s41467-021-21249-6.

[22] Brooks-Pollock E, Read JM, McLean AR, Keeling MJ, Danon L. Mapping social distancing measures to the reproduction number for covid-19. Philosophical Transactions of the Royal Society $B$ 376(1829):20200276 (2021).

[23] Flasche S, Edmunds WJ. The role of schools and school-aged children in SARS-CoV-2 transmission. Lancet Infect. Dis. 21(3):298-299 (2021). doi:10.1016/S1473-3099(20)30927-0.

[24] Asgary A, Cojocaru MG, Najafabadi MM, Wu J. Simulating preventative testing of SARS-CoV-2 in schools: policy implications. BMC Public Health 21(1):1-18 (2021).

[25] Rozhnova G, van Dorp CH, Bruijning-Verhagen P, Bootsma MC, van de Wijgert JH, et al. Modelbased evaluation of school-and non-school-related measures to control the covid-19 pandemic. Nature Communications 12(1614) (2021). doi:10.1038/s41467-021-21899-6.

[26] McGee RS, Homburger JR, Williams HE, Bergstrom CT, Zhou AY. Model-driven mitigation measures for reopening schools during the covid-19 pandemic. P.N.A.S. 118:e2108909118 (2021).

[27] Woodhouse MJ, Aspinall WP, Sparks SR, et al. Analysis of alternative covid-19 mitigation measures in school classrooms: an agent-based model of sars-cov-2 transmission. medRxiv (2021). 
medRxiv preprint doi: https://doi.org/10.1101/2022.02.04.22270361; this version posted February 6, 2022. The copyright holder for this preprint (which was not certified by peer review) is the author/funder, who has granted medRxiv a license to display the preprint in It is made available under a CC-BY-NC-ND 4.0 International license .

[28] Wong BLH, Ramsay ME, Ladhani SN. Should children be vaccinated against covid-19 now? Archives of Disease in Childhood (2021).

[29] Zimmermann P, Pittet LF, Finn A, Pollard AJ, Curtis N. Should children be vaccinated against covid-19? Archives of disease in childhood (2021).

[30] Gurdasani D, Bhatt S, Costello A, Denaxas S, Flaxman S, et al. Vaccinating adolescents against sars-cov-2 in england: a risk-benefit analysis. Journal of the Royal Society of Medicine 114(11):513-524 (2021).

[31] Ladhani SN, sKIDs Investigation Team. Children and covid-19 in schools. Science 374(6568):680$682(2021)$.

[32] Smith A, Coles S, Johnson S, Saldana L, Ihekweazu C, et al. An outbreak of influenza a (h1n1) v in a boarding school in south east england, may-june 2009. Eurosurveillance 14(27):19263 (2009).

[33] Cauchemez S, Ferguson NM, Wachtel C, Tegnell A, Saour G, et al. Closure of schools during an influenza pandemic. The Lancet infectious diseases 9(8):473-481 (2009).

[34] Schmidt W, Pebody R, Mangtani P. School absence data for influenza surveillance: a pilot study in the united kingdom. Eurosurveillance 15(3):19467 (2010).

[35] Wichmann O, Hellenbrand W, Sagebiel D, Santibanez S, Ahlemeyer G, et al. Large measles outbreak at a german public school, 2006. The Pediatric infectious disease journal 26(9):782-786 (2007).

[36] Paunio M, Peltola H, Valle M, Davidkin I, Virtanen M, et al. Explosive school-based measles outbreak: intense exposure may have resulted in high risk, even among revaccinees. American journal of epidemiology 148(11):1103-1110 (1998).

[37] Mossong J, Hens N, Jit M, Beutels P, Auranen K, et al. Social Contacts and Mixing Patterns Relevant to the Spread of Infectious Diseases. PLoS Med. 5(3):e74 (2008). doi:10.1371/journal. pmed.0050074.

[38] Prem K, Liu Y, Russell TW, Kucharski AJ, Eggo RM, et al. The effect of control strategies to reduce social mixing on outcomes of the COVID-19 epidemic in Wuhan, China: a modelling study. Lancet Public Heal. (2020). doi:10.1016/S2468-2667(20)30073-6.

[39] Danon L, Read JM, House TA, Vernon MC, Keeling MJ. Social encounter networks: characterizing Great Britain. Proc. R. Soc. B Biol. Sci. 280(1765):20131037 (2013). doi:10.1098/rspb.2013. 1037.

[40] Mensah AA, Sinnathamby M, Zaidi A, Coughlan L, Simmons R, et al. SARS-CoV-2 infections in children following the full re-opening of schools and the impact of national lockdown: Prospective, national observational cohort surveillance, July-December 2020, England. J. Infect. 82(4):67-74 (2021). doi:10.1016/j.jinf.2021.02.022.

[41] Heavey L, Casey G, Kelly C, Kelly D, McDarby G. No evidence of secondary transmission of COVID-19 from children attending school in Ireland, 2020. Eurosurveillance 25(21):pii=2000903 (2020). doi:10.2807/1560-7917.ES.2020.25.21.2000903.

[42] Southall E, Holmes A, Hill EM, Atkins BD, Leng T, et al. An analysis of school absences in england during the covid-19 pandemic. BMC medicine 19(1):1-14 (2021). 
medRxiv preprint doi: https://doi.org/10.1101/2022.02.04.22270361; this version posted February 6, 2022. The copyright holder for this preprint (which was not certified by peer review) is the author/funder, who has granted medRxiv a license to display the preprint in

It is made available under a CC-BY-NC-ND 4.0 International license .

[43] Brandal LT, Ofitserova TS, Meijerink H, Rykkvin R, Lund HM, et al. Minimal transmission of SARS-CoV-2 from paediatric COVID-19 cases in primary schools, Norway, August to November 2020. Eurosurveillance 26(1):pii=2002011 (2021). doi:10.2807/1560-7917.ES.2020.26.1.2002011.

[44] Stein-Zamir C, Abramson N, Shoob H, Libal E, Bitan M, et al. A large covid-19 outbreak in a high school 10 days after schools' reopening, israel, may 2020. Eurosurveillance 25(29):2001352 (2020).

[45] Zimmerman KO, Akinboyo IC, Brookhart MA, Boutzoukas AE, McGann KA, et al. Incidence and secondary transmission of sars-cov-2 infections in schools. Pediatrics 147(4) (2021).

[46] Molteni E, Sudre CH, Canas LS, Bhopal SS, Hughes RC, et al. Illness duration and symptom profile in a large cohort of symptomatic uk school-aged children tested for sars-cov-2. The Lancet Child and Adolescent Health (2021).

[47] Chudasama DY, Tessier E, Flannagan J, Leeman D, Webster H, et al. Surge in sars-cov-2 transmission in school-aged children and household contacts, england, august to october 2021. Eurosurveillance 26(48):2101019 (2021).

[48] Keeling MJ, Hill EM, Gorsich EE, Penman B, Guyver-Fletcher G, et al. Predictions of COVID19 dynamics in the UK: Short-term forecasting and analysis of potential exit strategies. PLOS Comput. Biol. 17(1):e1008619 (2021). doi:10.1371/journal.pcbi.1008619.

[49] Keeling MJ, Dyson L, Guyver-Fletcher G, Holmes A, Semple MG, et al. Fitting to the UK COVID-19 outbreak, short-term forecasts and estimating the reproductive number. Statistical Methods in Medical Research (Special Issue: Pandemics):09622802211070257 (2022). doi:10.1177/ 09622802211070257.

[50] Moore S, Hill EM, Tildesley MJ, Dyson L, Keeling MJ. Vaccination and non-pharmaceutical interventions for COVID-19: a mathematical modelling study. Lancet Infect. Dis. 21(6):793-802 (2021). doi:10.1016/S1473-3099(21)00143-2.

[51] Keeling MJ, Thomas A, Hill EM, Thompson RN, Dyson L, et al. Waning, Boosting and a Path to Endemicity for SARS-CoV-2. medRxiv page 2021.11.05.21265977 (2021). doi:https: //doi.org/10.1101/2021.11.05.21265977.

[52] Moore S, Keeling MJ. Roadmaps for Relaxation of NPIs (2021). URL https: //assets.publishing.service.gov.uk/government/uploads/system/uploads/attachment_data/ file/963444/S1118_Roadmaps_for_relaxation_of_NPIs__Warwick.pdf.

[53] Keeling MJ, Dyson L, Hill E, Moore S, Tildesley M. RRoad Map Scenarios and Sensitivity: Step 4 (2021). URL https://assets.publishing.service.gov.uk/government/uploads/system/ uploads/attachment_data/file/1001172/S1302_University_of_Warwick_Road_Map_Scenarios_and_ Sensitivity_Step_4.2__6_July_2021____.pdf.

[54] Leng T, Hill EM, Thompson RN, Tildesley MJ, Keeling MJ, et al. Assessing the impact of secondary school reopening strategies on within-school COVID-19 transmission and absences: a modelling study. medRxiv page 2021.02.11.21251587 (2021). doi:10.1101/2021.02.11.21251587.

[55] Kunzmann K, Lingjaerde C, Bird S, Richardson S. The 'how' matters: A simulation-based assessment of the potential contributions of LFD tests for school reopening in England. ArXiv e-prints (2021). 
medRxiv preprint doi: https://doi.org/10.1101/2022.02.04.22270361; this version posted February 6, 2022. The copyright holder for this preprint (which was not certified by peer review) is the author/funder, who has granted medRxiv a license to display the preprint in It is made available under a CC-BY-NC-ND 4.0 International license .

[56] Dyson L, Hill EM, Moore S, Curran-Sebastian J, Tildesley MJ, et al. Possible future waves of sars-cov-2 infection generated by variants of concern with a range of characteristics. Nature Communications 12:5730 (2021).

[57] UKHSA. Covid-19 vaccine weekly surveillance reports (2021). URL https: //www.gov.uk/government/publications/covid-19-vaccine-weekly-surveillance-reports\# full-publication-update-history.

[58] Lopez Bernal J, Andrews N, Gower C, Gallagher E, Simmons R, et al. Effectiveness of covid-19 vaccines against the b. 1.617. 2 (delta) variant. $N$ Engl $J$ Med pages 585-594 (2021).

[59] JCVI. COVID-19 vaccination of children and young people aged 12 to 17 years: JCVI statement 4th August 2021 (2021). URL https://www.gov.uk/government/publications/ covid-19-vaccination-of-children-and-young-people-aged-12-to-17-years-jcvi-statement.

[60] JCVI. COVID-19 vaccination of children and young people aged 12 to 17 years: JCVI statement 25th October 2021 (2021). URL https://www.gov.uk/government/publications/ jcvi-statement-august-2021-covid-19-vaccination-of-children-and-young-people-aged-12-to-17-years/.

[61] JCVI. COVID-19 vaccination in children and young people aged 16 to 17 years: JCVI statement 15th November 2021 (2021). URL https://www.gov.uk/government/publications/ covid-19-vaccination-in-children-and-young-people-aged-16-to-17-years-jcvi-statement-november-2021.

[62] JCVI. JCVI update on advice for COVID-19 vaccination of children and young people: JCVI statement 22nd December 2021 (2021). URL https://www.gov.uk/government/publications/ jcvi-update-on-advice-for-covid-19-vaccination-of-children-and-young-people.

[63] JCVI. COVID-19 vaccination of children aged 12 to 15 years: JCVI statement 3rd September 2021 (2021). URL https://www.gov.uk/government/publications/ covid-19-vaccination-of-children-and-young-people-aged-12-to-17-years-jcvi-statement.

[64] JCVI. UK vaccine response to the Omicron variant: JCVI advice 29th November (2021). URL https://www.gov.uk/government/publications/ uk-vaccine-response-to-the-omicron-variant-jcvi-advice.

[65] Saadi N, Chi Y, Ghosh S, Eggo RM, McCarthy CV, et al. Models of covid-19 vaccine prioritisation: a systematic literature search and narrative review. BMC medicine 19(1):1-11 (2021).

[66] Moore S, Hill EM, Dyson L, Tildesley M, Keeling MJ. Modelling optimal vaccination strategy for SARS-CoV-2 in the UK. medRxiv page 2020.09.22.20194183 (2020). doi:10.1101/2020.09.22. 20194183.

[67] Ward J, Harwood R, Smith C, Kenny SE, Clark M, et al. Risk factors for intensive care admission and death amongst children and young people admitted to hospital with covid-19 and pims-ts in england during the first pandemic year. medRxiv (2021).

[68] Szucs T. Cost-benefits of vaccination programmes. Vaccine 18:S49-S51 (2000).

[69] Park M, Jit M, Wu JT. Cost-benefit analysis of vaccination: a comparative analysis of eight approaches for valuing changes to mortality and morbidity risks. BMC medicine 16(1):1-11 (2018).

[70] Luyten J, Kessels R, Atkins KE, Jit M, Van Hoek AJ. Quantifying the public's view on social value judgments in vaccine decision-making: A discrete choice experiment. Social Science 8 Medicine 228:181-193 (2019). 
medRxiv preprint doi: https://doi.org/10.1101/2022.02.04.22270361; this version posted February $6,2022$. The copyright holder for this preprint (which was not certified by peer review) is the author/funder, who has granted medRxiv a license to display the preprint in It is made available under a CC-BY-NC-ND 4.0 International license .

[71] Bozkurt B, Kamat I, Hotez PJ. Myocarditis with COVID-19 mRNA vaccines. Circulation 144(6):471-484 (2021).

[72] Diaz GA, Parsons GT, Gering SK, Meier AR, Hutchinson IV, et al. Myocarditis and pericarditis after vaccination for covid-19. Jama 326(12):1210-1212 (2021).

[73] Montgomery J, Ryan M, Engler R, Hoffman D, McClenathan B, et al. Myocarditis following immunization with mrna covid-19 vaccines in members of the us military. JAMA cardiology 6(10):1202-1206 (2021).

[74] Mouch SA, Roguin A, Hellou E, Ishai A, Shoshan U, et al. Myocarditis following covid-19 mrna vaccination. vaccine (2021).

[75] Nalbandian A, Sehgal K, Gupta A, Madhavan MV, McGroder C, et al. Post-acute covid-19 syndrome. Nature medicine 27(4):601-615 (2021).

[76] Lopez-Leon S, Wegman-Ostrosky T, Perelman C, Sepulveda R, Rebolledo PA, et al. More than 50 long-term effects of covid-19: a systematic review and meta-analysis. Scientific Reports 11:16144 (2021). 
medRxiv preprint doi: https://doi.org/10.1101/2022.02.04.22270361; this version posted February 6, 2022. The copyright holder for this preprint (which was not certified by peer review) is the author/funder, who has granted medRxiv a license to display the preprint in

It is made available under a CC-BY-NC-ND 4.0 International license .

\section{Figures}

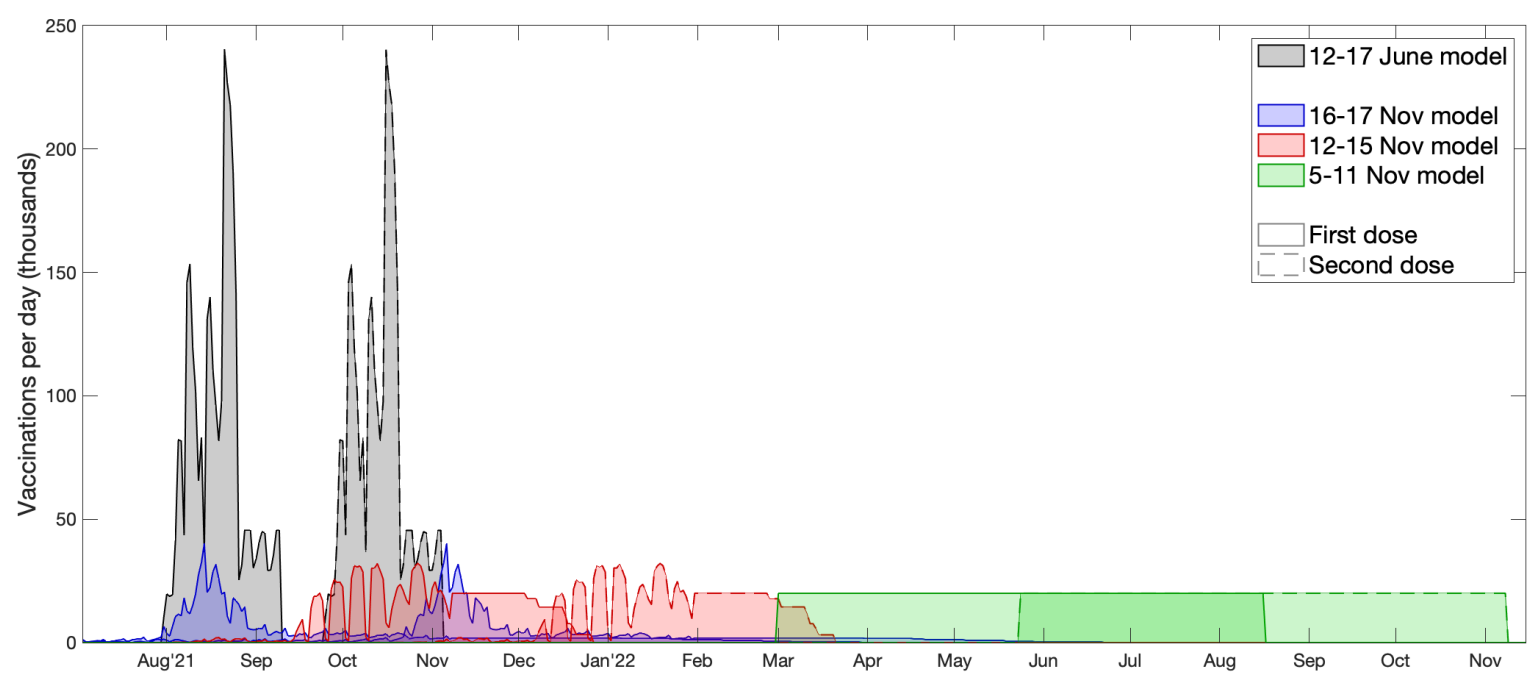

Fig. 1: Timing of vaccine delivery in the two models (June: black, November: blue, red, green) by target age-group. Solid outlines correspond to first doses, while dashed outlines correspond to second doses. For the November model, results are shown for the default assumption of 140,000 vaccines per week through the school delivery programme, and a $70 \%$ uptake.
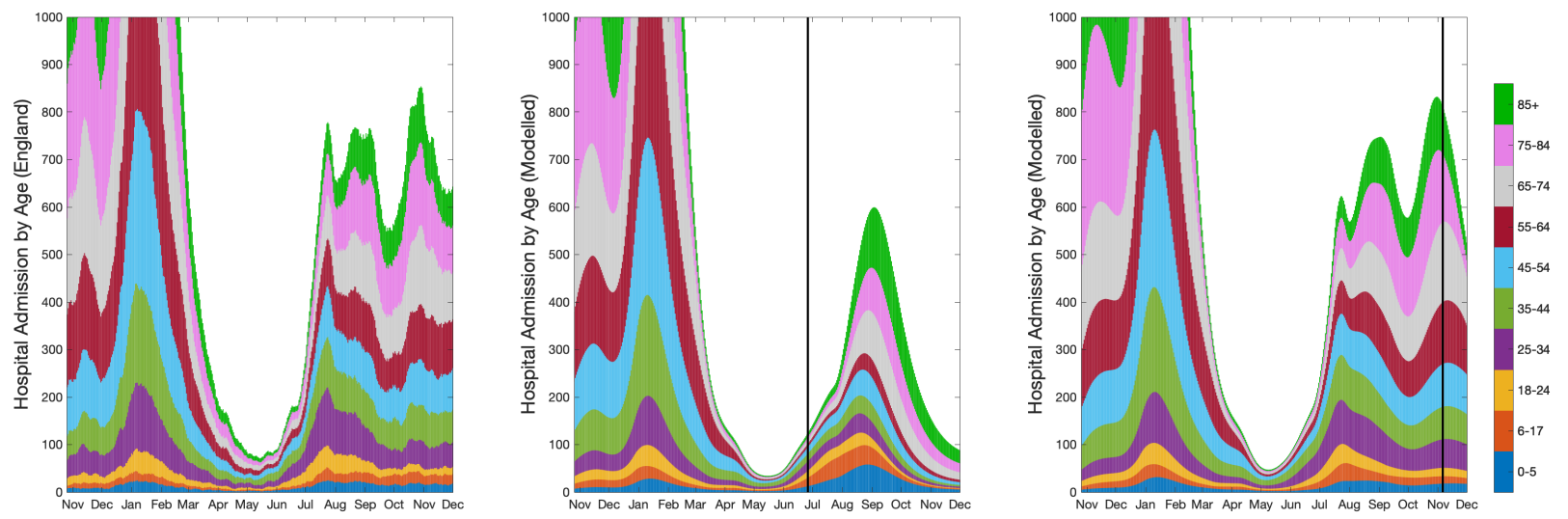

Fig. 2: Comparison of data (left) and model results (June: centre, November: right) for the number of daily hospital admissions in ten age groups, from 0-5 years to 85 and above. The data on the left is a one-week moving average (using 3 days either side of the date) which removes any day-of-the-week effects and helps to smooth stochastic fluctuations. The model results are from the both June (average over seven Step 4 mixing scenarios) and November predictions and are computed using 5-year age-classes, and as such the first three age-groups shown are composites of multiple simulated age-classes: the 0-5 age group contains all projected hospital admissions from the 0-4 age-class and one fifth of all admissions from the 5-9 age-class. The vertical lines corresponds to the simulation dates for the two projections - 26th June and 6th November 2021. 

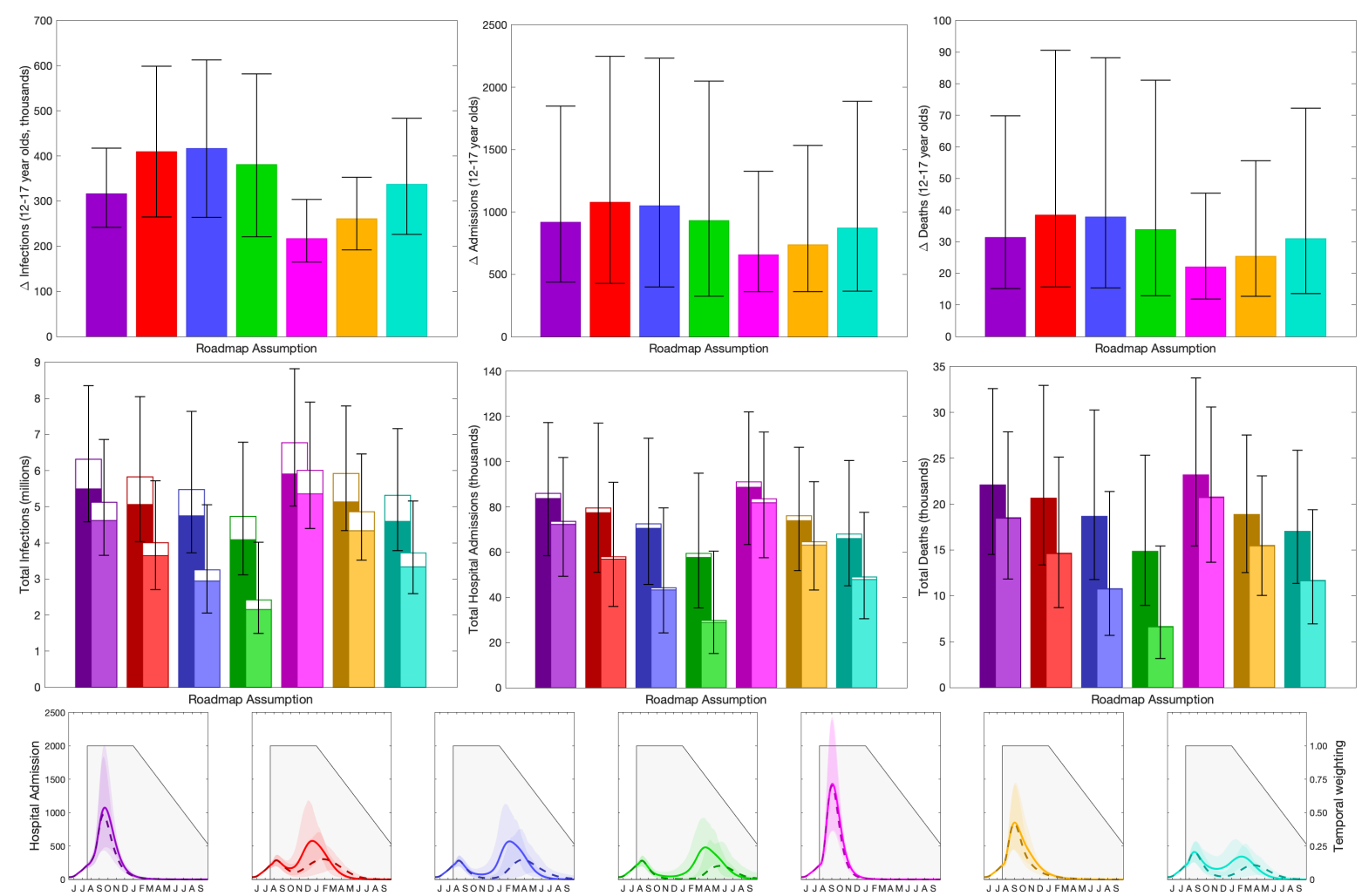

Fig. 3: Impact of vaccination of 12-17 year olds in England, calculated in June 2021. Top row: reduction in infections, hospital admissions and deaths in 12-17 year olds due to vaccination in this age-group. Middle row: total number of infections, hospital admissions and deaths in the entire population (total bar) and 12-17 year olds (open bar). Lower row: number of projected hospital admissions over time (lines and ribbons), and the assumed time discounting (grey shading). In the top two rows bars are the mean value, error bars are the $95 \%$ prediction intervals, and different colours represent different assumptions about precautionary mixing in Step 4 [53] 

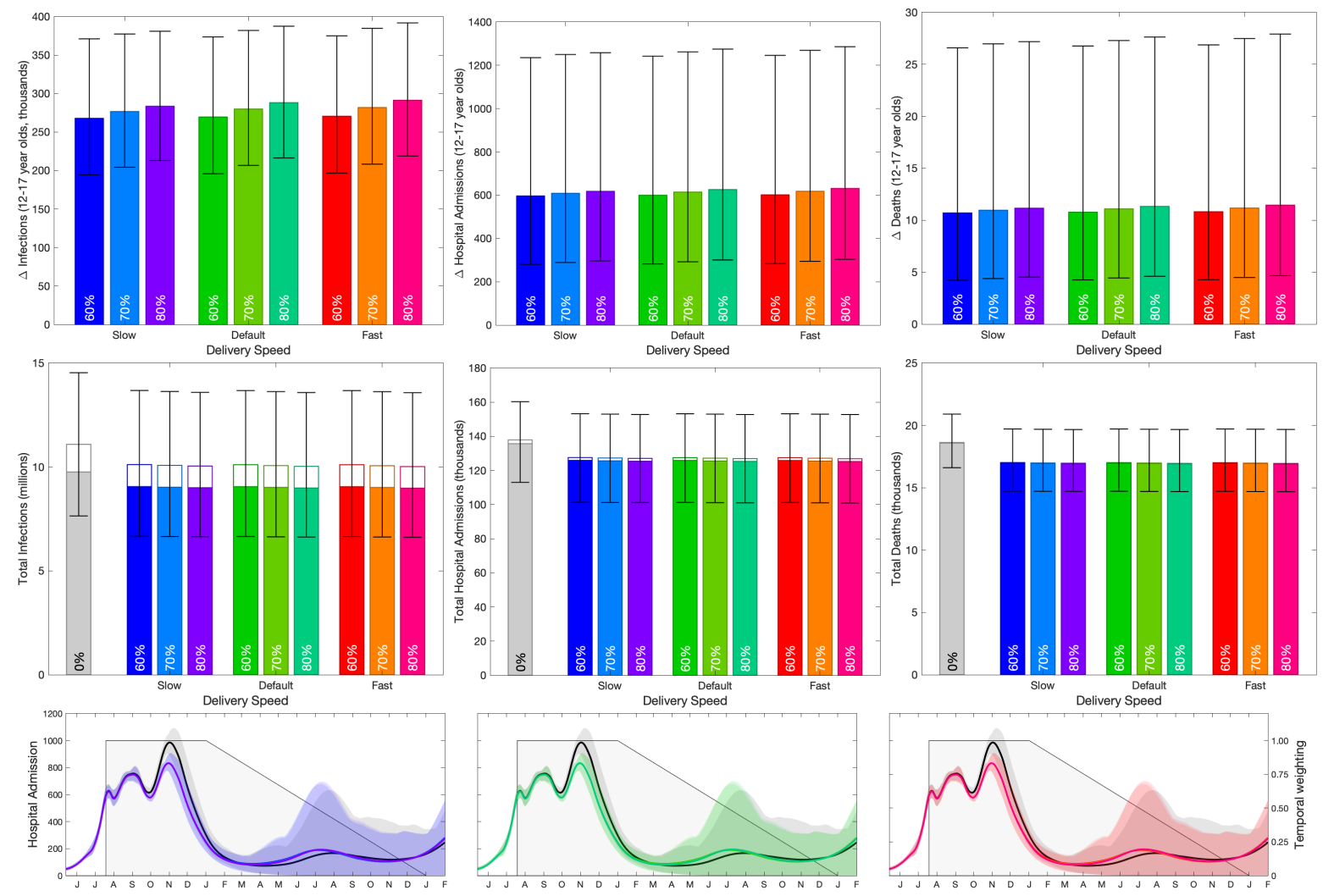

Fig. 4: Impact of vaccination of 12-17 year olds in England, calculated in November 2021. Top row: reduction in infections, hospital admissions and deaths in 12-17 year olds due to vaccination in this age-group. Middle row: total number of infections, hospital admissions and deaths in the entire population (total bar) and 12-17 year olds (open bar). Lower row: number of projected hospital admissions over time (lines and ribbons; black for without childhood vaccination, colours corresponding to the bars above with $70 \%$ uptake and default speed), and the assumed time discounting (grey shading). In the top two rows bars are the mean value, error bars are the $95 \%$ prediction intervals, and different colours represent different assumptions about uptake in 12-15 year olds (no vaccination, $60 \%, 70 \%$ and $80 \%$ ) and different assumptions about vaccine delivery speed (slow 100,000 per week, default - 140,000 per week, fast - 180,000 per week). In 16-17 year olds, uptake was based on observations up to mid November except the counterfactual of no vaccination in which case all vaccination in 12-17 year olds were removed. 

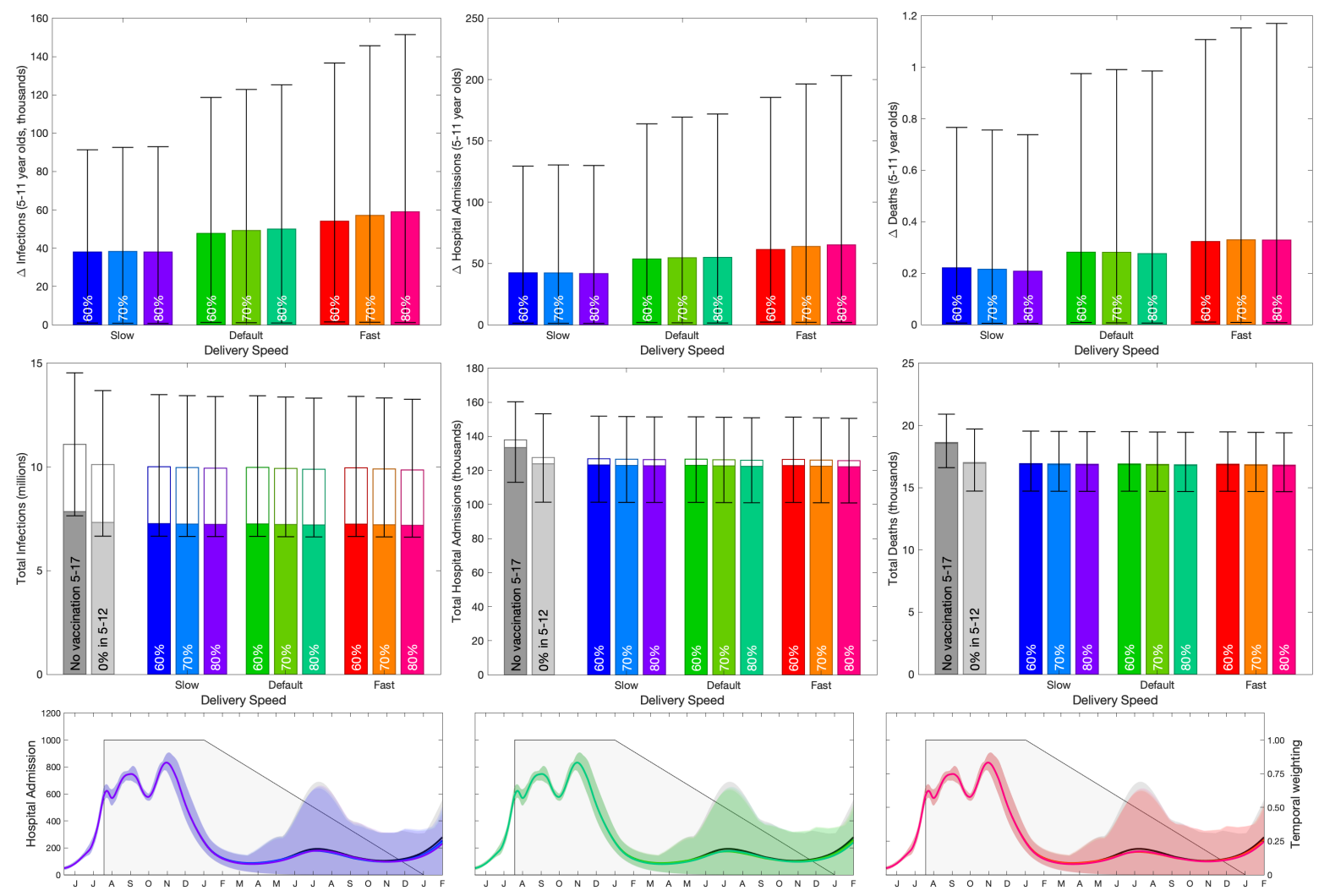

Fig. 5: Impact of vaccination of 5-11 year olds in England, calculated in November 2021. Top row: reduction in infections, hospital admissions and deaths in 5-11 year olds due to vaccination in this age-group. Middle row: total number of infections, hospital admissions and deaths in the entire population (total bar) and 5-17 year olds (open bar). Lower row: number of projected hospital admissions over time (lines and ribbons; black for vaccinating those aged 12 and above but not 5-11 year olds, colours corresponding to the bars in the above rows), and the assumed time discounting (grey shading). In the upper two rows bars are the mean value, error bars are the $95 \%$ prediction intervals, and different colours represent different assumption about uptake in 5-17 year olds (no vaccination, $60 \%, 70 \%$ and $80 \%$ ) and different assumptions about vaccine delivery speed (slow - 100,000 per week, default - 140,000 per week, fast - 180,000 per week). In the lower row, the counterfactual of no vaccination in all 5-17 year olds (dark grey) and the vaccination of 12-17 but not 5-11 (light grey) are both shown. 
medRxiv preprint doi: https://doi.org/10.1101/2022.02.04.22270361; this version posted February 6 , 2022. The copyright holder for this preprint (which was not certified by peer review) is the author/funder, who has granted medRxiv a license to display the preprint in It is made available under a CC-BY-NC-ND 4.0 International license.

\section{Additional Files}

\section{Additional file 1 - June Projections with shorter time window}

Figure showing the original assessment of vaccinating 12-17 year olds, shared with JCVI in June 2020, with used a much shorter and more abrupt time window - weighting all values between 19th July and 31st December 2021 equally.

\section{Additional file 2 - Model Formulation}

Detail of the underlying mathematical framework that defines the transmission model. We break the model desciption into multiple sections that combine to generate a picture of SARS-CoV-2 transmission in the UK. 